\section{Hans Oeschger (1927-98)}

\section{Pioneer in environmental physics}

The research of Hans Oeschger, who died on 25 December 1998 after a long illness, centred on applying the methods of modern physics to investigations of the Earth system. In particular, he and his team in Bern produced a stream of results that have become cornerstones of studies on climate change.

Oeschger was trained as an experimental physicist at ETH Zürich, and learned to appreciate the simplicity of physical laws. But he also recognized the limitations of the classical method in trying to dissect a system into its components, whereby processes fundamental to understanding the system in its entirety are lost. In F. G. Houtermans in Bern he found the right mentor for his dissertation: "Oeschger wanted to become a musician. However, since I do physics much like an artist, he now feels quite comfortable in physics".

The goal of Oeschger's dissertation was to build a $\beta$-counter to measure ultra-low radioactivity by counting the electrons emitted during decay. In 1955 he completed this device, now known as the Oeschger counter. It had a lower background than any other available instrument, due to a clever anticoincidence technique which dismissed counts that were not caused by the decaying sample, and became for many years the leading instrument in radiocarbon laboratories. In 1959, using this device, Oeschger, Suess and Rakestraw were the first to succeed in radiocarbondating Pacific deep water. They went on to measure the activity of a variety of naturally occurring radioisotopes, and embarked on a long journey to quantify the numerous exchange processes between different components of the Earth system.

In 1962 Oeschger started to determine the tritium contents of firn (unconsolidated snow) and ice, for use as archives of environmental information. His involvement in expeditions to Greenland and Antarctica between 1964 and 1992 gave his laboratory direct access to polar ice cores. The analytical methods and the drilling techniques that Oeschger and his team devised enabled them to produce an unprecedented reconstruction of climate changes of the past 150,000 years.

Oeschger was a leading figure in icecore research and one of the fathers of the deep-drilling projects Dye 3 and GRIP in

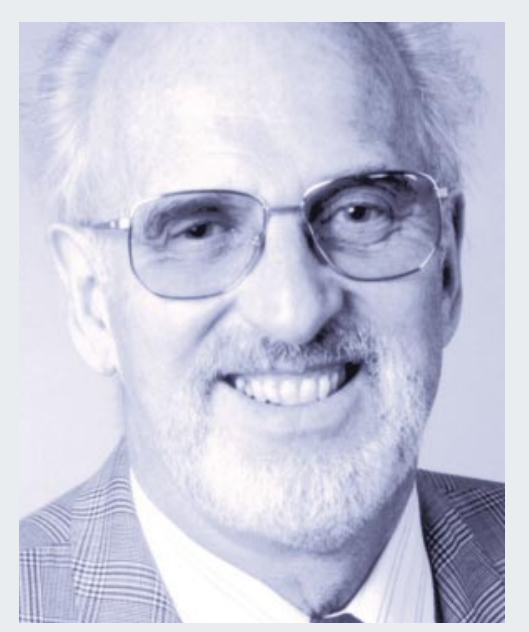

Greenland. Along with his colleagues he was the first to measure the glacial-interglacial change in levels of atmospheric $\mathrm{CO}_{2}$. In 1979 they showed that the atmospheric concentration of $\mathrm{CO}_{2}$ during the last glacial period was almost $50 \%$ lower than today. Furthermore, they analysed the $\mathrm{CO}_{2}$ changes during the past 1,000 years and showed that the dramatic increase in industrial times is a direct consequence of the burning of fossil fuels.

Hans Oeschger was troubled by the potentially adverse consequences of an increased greenhouse effect caused by the steady rise in atmospheric $\mathrm{CO}_{2}$. His early insight was based on a novel geochemical box-diffusion model for the global carbon cycle that his team developed. He also took his wider responsibilities as a scientist very seriously: "The worst for me," he declared, "would be if there were serious changes in the next five to ten years and we scientists ... did not have the courage to point out these dangerous developments early on". He gave many public lectures on this and other topics, and was also a lead author of the First Assessment Report of the Intergovernmental Panel on Climate Change.

There were even more surprises to come from the Greenland ice cores. Together with Chester C. Langway in the United States and Willi Dansgaard in Denmark, Oeschger documented a series of abrupt climate changes in the cores. Stable isotope measurements on carbonate sediments from Lake Gerzensee, near Bern, showed that these changes were not only local to Greenland but reflected large climatic swings of at least hemispheric extent. Twenty-four such swings, termed Dansgaard-Oeschger events, are evident during the last glacial in many different palaeoclimatic archives.

As long ago as 1984, Oeschger recognized the importance of ocean circulation in explaining abrupt climate change and used the physical analogy of a flip-flop system — triggered by small perturbations, the ocean circulation might switch from one circulation mode to another. Based on these insights, he was among the first to point out that the anthropogenic increase of $\mathrm{CO}_{2}$ could represent such a perturbation. Although his early warnings were often greeted with disbelief, the latest results from both observations and high-resolution palaeoclimate archives are an impressive testimony to his forward thinking on global warming.

One of Oeschger's great strengths was his recognition that the Earth must be seen as a complex system. Long before interand transdisciplinarity became buzzwords, his physical intuition and readiness to listen allowed him to weave links between seemingly disconnected observations and concepts. Hans's personal warmth and enthusiasm led to many fruitful collaborations across disciplinary boundaries. But he was always firm in pointing out that successful transdisciplinary research needs input of the highest quality from the disciplines concerned. The wide respect in which he was held stemmed, not least, from his own fundamental contributions to physics.

We owe much to Hans Oeschger. He would disguise his often challenging suggestions with the gentle and informal Swiss-German phrase, "Das sötted mir doch chöne mässe" ("We ought to be able to measure this"), words that on many occasions marked the beginning of a novel method to quantify environmental processes. With this approach, his contributions to palaeoclimatology transformed a descriptive field into a science in which changes of environmental conditions can be given numbers and units. His results and way of thinking will guide us on our way for a long time yet. Moreover he saw his science as being of wider service: "Real progress in this field will make it possible for society to act based on foresight. The anticipated climate change is only one of the great problems with which society is faced; the thorough way climate change is assessed by the scientific community may serve as an example for addressing other grand challenges". Those privileged to have worked or shared ideas with him will not forget his friendship.

\section{Thomas Stocker}

Thomas Stocker is in Climate and Environmental Physics, Physics Institute, University of Bern, Sidlerstrasse 5, CH-3012 Bern, Switzerland. e-mail:stocker@climate.unibe.ch 